\title{
Study on the Role of Dragon Dance in Campus Culture
}

\author{
Yaohui Lin \\ Xiamen University Tan Kah Kee College \\ Xiamen, China
}

\begin{abstract}
Dragon dance is an ancient movement. In the process of development, it has gradually become a ritual in people's sacrifices and festivals. With the influx of Western culture in modern times, the frequency of dragon dance in life is relatively reduced. To certain extent, this has posed a negative impact on our traditional sports and inhibited the development of traditional culture. This situation urgently needs to be solved to enhance the development of traditional culture in schools. This paper studies the current situation of the development of dragon dance in colleges and universities through literature and interviewing experts and logic reasoning methods, in order to improve the role of dragon dance in the construction of campus culture through the study of dragon dance, and strengthen students' understanding of traditional culture, enhance the patriotic education and strengthen students' sense of national pride and activates the campus culture.
\end{abstract}

Keywords—dragon dance; campus; culture; role

\section{INTRODUCTION}

The dragon dance is a relatively old sport in China. It plays an important role in the history. Whether it is in sacrifice or in festivals, the importance of dragon dance is self-evident. With the influx of Western sports, traditional sports have been in a low tide for a certain period of time. At this stage, the state has gradually paid more attention to the development of traditional culture and traditional sports. By starting traditional dances such as dragon dance and lion dance in colleges and universities, students can effectively enhance their The love of traditional culture enhances national pride and at the same time effectively enhances the physical quality of students and promotes the development of students' comprehensive quality. However, through the investigation of the current situation of dragon and lion dance in colleges and universities, it is found that the development of dragon and lion dance in colleges and universities is not enough. It is necessary to improve the development of dragon dance in colleges and universities through the efforts of society, schools and individuals. The social level pays more attention to the development of the dragon dance in the school; the school increases the propaganda of the dragon dance movement and establishes the association; the individual learns and trains the dragon dance through the association or elective courses in the school, enhances the sports skills and enhances the physical fitness.

\section{RESEARCH METHOD}

\section{A. Literature Consultation}

More than 30 articles on dragon dance and campus culture construction were reviewed through CNKI and Xiamen university library.

\section{B. Expert Interview}

In order to better form the thesis, in the process of writing, 8 experts in the field of dragon dance and campus culture construction were interviewed in form of face-to-face interviews and telephone interviews.

C. Logic Analysis

Use language to analyze and solve traditional philosophical problems through language analysis.

\section{PURPOSE AND SIGNIFICANCE}

\section{A. Purpose}

Through the current situation of the development of dragon dance on campus, explore the role of dragon dance in the construction of campus culture.

\section{B. Research Significance}

By studying the role of dragon dance in the construction of colleges and universities, the paper further improves the work of dragon dance in colleges and universities and provides referential Suggestions and opinions for improving the construction of school culture.

\section{RESEARCH CONTENTS}

\section{A. The Concept and Origin of Dragon Dance}

Dragon dance is commonly known as playing the dragon lantern. It is one of the traditional folk cultural activities of the Chinese nation. With the development of society, dragon dance has gradually become one of the important contents of festivals and sacrificial activities. When dragon dances, the dragon follows hydrangea to do various movements, interweaving and constantly displaying various gestures such as twisting, waving, lifting, kneeling, jumping and shaking. 
In ancient times, dragon dance became a way for people to pray for peace and harvest.

The origin of the dragon dance movement has an important relationship with the ancient prayer rain. The ancient China was mainly based on agriculture. In ancient agriculture, it was mainly to watch the heavens. Rain was considered to be the most important factor for agriculture and could determine the growth of crops. The dragon is considered to be the god who decides the rain. From the fear of the gods and the yearning for the good life, the cloak of witchcraft is deeply wrapped in the need for the rain. This is the original cultural origin of the dragon.

\section{B. The Status Quo of Dragon Dance on Campus}

As one of the oldest projects in China, the dragon dance has been loved by the people. However, like other ethnic projects, with the changes in the social environment and the influx of Western culture, the dragon dance has once lost its survival in China. Colleges and universities are places for cultivating people's all-round development. They have an important leading role in the inheritance of future social culture. As a traditional Chinese culture, the dragon dance movement is important for the cultivation of students' physical quality, team awareness and patriotism. Upgrading is also of great significance for enriching and strengthening campus culture.

Through the investigation of some college dragon dance sports, it is found that the number of schools that carry out dragon dance in colleges and universities is relatively small at present. Even if some schools carry out dragon dance, the number of participants in the school is not many. The reason for this phenomenon is many aspects. There are students' problems in understanding and the reasons for the promotion and promotion of the dragon dance. Due to the lack of promotion and promotion of the dragon dance movement, the students are not fully aware of the dragon dance movement. Many students really want to participate in the dragon dance movement. It is also almost impossible to find a suitable platform. The current situation is extremely unfavorable for the development of the dragon dance in schools. Schools should increase their propaganda on the dragon dance movement and provide students with a platform to participate in the dragon dance movement, so that the dragon dance movement is close to the student's life.

\section{Relevant Concepts and Related Content of Campus Culture}

The campus culture is based on students, with extracurricular cultural activities as the main content. The campus is the main space, including college leaders, faculty and staff, and a group culture with campus spirit as the main feature. Campus culture is part of the overall culture of society. Campus culture is generally derived from the meaning of the school's spiritual culture. From a macro perspective, campus culture mainly includes three aspects such as material culture, spiritual culture and institutional culture of the school. These three contents are complementary to each other to certain extent; one culture promotes the formation and development of another culture. The mutual coordination promotes the long-term development of the school, enhances the visibility of the school, and promotes the construction and development of the campus culture.

Campus culture plays an important role and role in the construction of the campus. A good campus culture can give people a good mood and mental state, so that students can have a positive attitude and a good spiritual outlook in this environment, learning and living. The positive is effectively increased, and the negative emotions are suppressed to some extent. Secondly, campus culture can have a stimulating effect on students. The school campus culture with positive energy plays an active role in the big environment. In this environment, students can encourage students to actively learn and enterprising, and encourage students to be enterprising. The spiritual level mainly shows the value orientation of a school's overall spirit and is an educational resource with guiding functions. Therefore, schools should attach great importance to the construction of school campus culture, enhance the connotation of school campus culture, and promote the improvement of teaching quality.

\section{The Role of Dragon Dance in the Construction of Campus Culture}

As one of the traditional cultures of our country, dragon dance has an important role and significance in many aspects such as inheritance, history and education. With the changes of society and environment, there has been a time when the dragon dance gradually faded out of sight. The society, especially the education-related departments, has increased the importance attached to the dragon dance movement. The dragon dance movement has gradually developed in colleges and universities. However, it is undeniable that there is still a certain distance between the development of dragon dance and sports compared with basketball and football. There is a long way to go, and the joint efforts of schools, associations, and students are needed to further enhance the development of the dragon dance. Through the combing of the dragon dance movement, it is found that the dragon dance movement plays an important role in the campus culture construction. It mainly analyzes and studies the role and influence of the dragon dance movement on the material, spiritual and institutional level of the campus culture, and explores the promotion of the dragon dance movement. The role, strategy and significance of school development, improve the campus culture construction, improve the development of dragon dance in schools, and promote the healthy development of students' physical and mental health.

1) The role of dragon dance in the material culture of campus: Material culture refers to the material products created by human beings, including production tools and labor objects, as well as technologies for creating material products. Material culture comes from technology and is directly related to the way in which social and economic activities are organized. It is shown through the economic, social, financial and market infrastructure. 
The construction of material culture can improve the quality of school running to a certain extent. Through the development of dragon dance in colleges and universities, the school's investment in the corresponding material facilities of dragon dance is enhanced. The quality and quantity guarantee of material level can stimulate students' exercise to the maximum extent. Interest and enthusiasm, the dragon dance sports and venue facilities are not high, only need a flat venue plus dragon-related equipment, in addition to the establishment of the dragon-related training venues on the campus, the purpose of training venues Mainly through the input of some auxiliary facilities, to attract more students to participate in the dragon dance movement, the increase and investment of facilities can meet the training of students participating in the exercise, thereby improving students' endurance, sensitivity, strength, speed, etc. In addition, the training of the dragon dance athletes can be open to all students, improve the enthusiasm of ordinary students in physical exercise, and let more students understand the dragon dance and participate in the dragon dance as much as possible to enhance the influence of dragon dance in the school.

2) The role of dragon dance in the spiritual of campus culture: Spirit refers to people's consciousness, thinking activities and general psychological state. The spiritual level is more inspiring to a certain extent. It gives people a strong sense of perseverance to accomplish things that ordinary people can't imagine. Through the development of the dragon dance in the school, it is available to promote the spirit of the culture, and promote the healthy growth of students' minds.

The dragon dance is a team project. In the dragon dance, the players cooperate with each other to complete a task. Through the dragon dance, the players can form a spirit of solidarity and courage. In the process of facing difficulties, the students interact with each other. They can motivate, work together, make decisions, and face challenges and tasks together. Long-term dragon dance training can enable students to form a positive and optimistic mental state, even if they are able to live and learn outside the dragon dance. Form a good consistent quality, enhance the mental outlook of students, and improve the personality of students to form a good personality and the courage to face setbacks.

3) The role of dragon dance on campus culture system: Institutional culture is an organized normative system that human beings actively create for their own survival and social development. It mainly includes administrative management system, talent training selection system, legal system and folk etiquette rules. System culture is one of the theoretical elements of cultural level. Institutional culture is the sum of various social relationships formed by human beings in the process of material production. The social legal system, political system, economic system, and various relations between people are the reflection of institutional culture.

Through the development of the dragon dance in the school, the school's concept of dragon dance management is improved, the management system is improved, and the dragon dance movement is getting better and better in the school. The dragon dance movement needs to be upgraded. Based on good reserve talents, the selection of dragon dance talents is the basic work of the dragon dance movement and the most important work. The selection of talents depends to a large extent on the number of students, and it is necessary to vigorously promote and excavate in schools. The theory of dragon dance sports enhances the enthusiasm and initiative of students to participate in the dragon dance movement. On the basis of a large number of reserve talents, it can effectively improve the efficiency of talent selection. Through the organization of the dragon dance competition to form a good sense of rules, students follow the corresponding rules and regulations of the dragon dance movement, and enhance the construction of institutional culture.

\section{E. Problems and Development Strategies of Dragon Dance in Campus Culture Construction}

1) Problems in the construction of campus culture by dragon dance: In the process of the development of things, some problems will inevitably arise. In the process of development, the development of the sport can be effectively promoted through the discovery of problems and the corresponding strategies for improvement. As an ancient movement in China, the dragon dance was once obstructed or even disappeared by various factors. In recent years, with the development of society and the emphasis on traditional culture, the dragon dance movement is on the right track. However, it is undeniable that there are still some difficulties in the development of the dragon dance in the current stage, mainly due to the lack of popularity of the dragon dance in schools and the low frequency of students participating in the dragon dance.

2) Strategies to improve the role of dragon dance in campus culture construction: In order to further enhance the development of the dragon dance in schools, it is necessary to increase the propaganda of the dragon dance through the school to enhance the influence of the sport in the school and the enthusiasm of the students to participate in the dragon dance. At the same time, organize the dance regularly in the school. The dragon-related competitions enhance the enthusiasm of the players and the enthusiasm of the training. The improvement of the training level can effectively enhance the viewing and difficulty of the competition, and plays an important role in improving the development of the dragon dance in the school.

\section{CONCLUSION}

At present, the number of schools that conduct dragon dance in colleges and universities is relatively small. The dragon dance movement plays an important role in the material culture, spiritual culture and institutional culture of campus culture. The problems in the construction of campus culture in the dragon dance are mainly reflected in the fact that the popularity of the dragon dance in the school is not 
enough, and the frequency of students participating in the dragon dance is low.

It is suggested that by increasing the propaganda, the influence of the dragon dance movement in the school will be enhanced, and the enthusiasm of the students to participate in the dragon dance movement will be mobilized. At the same time, the dragon dance competition is regularly organized in the school to improve the treatment of the dragon dance athletes through social sponsorship, and to enhance the enthusiasm of the players and the enthusiasm for training.

\section{REFERENCES}

[1] Tan Guangxin and so on. Wufeng Wuying: A field investigation report on the excavation and consolidation of the Yi people in the south [J]. Sports Science, 2014, 34 (3): 67.

[2] Li Liyan. The philosophical declaration of sports - "the naturalization of man" [J]. Journal of Tianjin Institute of Physical Education, 1994, 9(1): 27-35.

[3] Pan Jiahua, Wei Houkai. City Blue Book: China's Urban Development Report No.5 - towards the green prosperity of the urban era [M]. Beijing: Social Sciences Academic Press, 2012: 5-10.

[4] Ye Jingzhong, Liu Yanli, etc. Participatory development planning [M]. Beijing: Social Sciences Academic Press, 2005: 295.

[5] Gao Bingzhong. The Chinese people's life world - the path of folklore [M]. Beijing: Peking University Press, 2010. 